\title{
Familial Thoracic Aortic Aneurysm and Dissection
}

\author{
Sabry Omar MD, Tyler Moore MD, Drew Payne DO, Zachary Mulkey MD
}

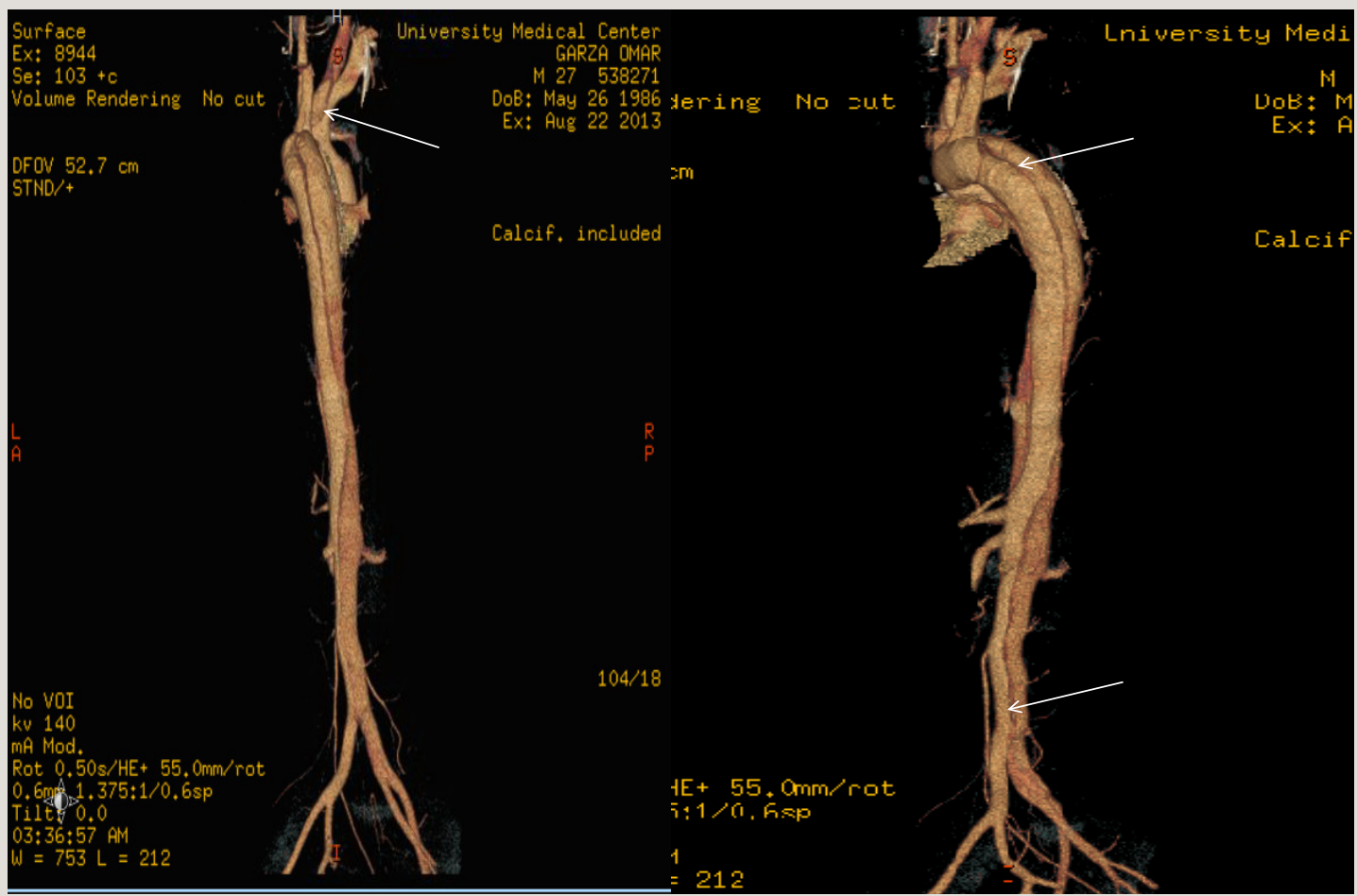

Figures 3-D reconstruction of second aortic aneurysm and dissection involving the carotid artery, thoracic aorta, and abdominal aorta.

\section{CASE}

A 26-year-old man had no significant past medical history but had a family history of dissecting aortic aneurysm in his mother at age 40. The patient had a normal physical appearance and did not have any features suggesting Marfan's syndrome, Ehlers-

Corresponding author: Sabry Omar MD

Contact Information: Sabry.Omar@ttuhsc.edu

DOI: 10.12746/swrccc 2014.0207.086
Danlos syndrome, Loeys-Dietz syndrome, ANCApositive vasculitis, or Takayasu's arteritis. He presented with cough, shortness of breath, and chest pain for 10 days. Chest x-ray at the time of presentation showed bilateral pulmonary infiltrates. ACT scan of the chest showed a dissecting aneurysm of the ascending aorta; the patient was transferred to our hospital and underwent a successful aortic aneurysm repair. The patient did well post-operatively and was discharged home on carvedilol $12.5 \mathrm{mg}$ twice a day. Three months after aortic dissection repair, the 
patient returned to our hospital with new complaints of sharp back pain. CT angiography with 3-D reconstruction showed a new aortic aneurysm and dissection extending from the carotid arteries through the bifurcation and into the right iliac artery (Figures). The patient underwent aortic, carotid, iliac arteries repair, and mechanical aortic valve replacement. He did well after surgery and was discharged home on warfarin, amlodipine, carvedilol, and losartan. The genetic studies for thoracic aortic aneurysm and dissection (TAAD) revealed no mutations.

\section{Discussion}

Aortic dissection usually occurs in older age groups but can occur in patients less than 60 years old. TAAD occurs at rate of 3 cases per 100,000 individuals per year and is a major cause of death in these patients. ${ }^{1}$ These conditions are autosomal dominant and display variable penetrance and severity. ${ }^{2}$ Albornoz studied 520 patients with thoracic aortic aneurysm and their families and found an inherited pattern for thoracic aortic aneurysm was present in $21.5 \%$ of the non Marfan's syndrome patients. Additionally, $20 \%$ of TAAD without known vascular connective tissue syndrome have at least one first degree family member with an arterial aneurysm. ${ }^{3}$ Despite negative genetic studies of the patient for TAAD, we believe that the patient has a gene mutation that has not been identified yet.

Author affiliation : Sabry Omar, Tyler Moore, and Drew Payne are residents in Internal Medicine at TTUHSC. Zachary Mulkey is a general internist in the Department of Internal Medicine.

Submitted: $4 / 9 / 2014$

Accepted: 5/7/2014

Reviewers: Aliakbar Arvandi MD

Conflict of Interest: None

Published electronically: 7/13/2014

\section{References}

1. Clouse WD, Hallett JW Jr, Schaff HV, et al. Acute aortic dissection: population-based incidence compared with degenerative aortic aneurysm rupture. Mayo Clin Proc 2004; 79:176. 2. Milewicz DM, Chen H, Park ES, et al. Reduced penetrance and variable expressivity of familial thoracic aortic aneurysms/ dissections. Am J Cardiol. 1998; 82:474-479.

3. Albornoz G1, Coady MA, Roberts M, et al. Familial thoracic aortic aneurysms and dissections--incidence, modes of inheritance, and phenotypic patterns. Ann Thorac Surg. 2006 Oct; 82(4):1400-5. 